\title{
Extremely severe space weather and geomagnetically induced currents in regions with locally heterogeneous ground resistivity
}

\author{
Shigeru Fujita ${ }^{1 *}$, Ryuho Kataoka ${ }^{2}$, Ikuko Fujii ${ }^{1}$, Antti Pulkkinen ${ }^{3}$ and Shinichi Watari ${ }^{4}$
}

Large geomagnetically induced currents (GICs) triggered by extreme space weather events are now regarded as one of the serious natural threats to the modern electrified society. The risk is described in detail in High-Impact, Low-Frequency Event Risk, A Jointly-Commissioned Summary Report of the North American Electric Reliability Corporation and the US Department of Energy's November 2009 Workshop, June 2010. For example, the March 13-14, 1989 storm caused a large-scale blackout affecting about 6 million people in Quebec, Canada, and resulting in substantial economic losses in Canada and the USA (Bolduc 2002). Therefore, European and North American nations have invested in GIC research such as the "Solar Shield project" in the USA (Pulkkinen et al. 2009, 2015a). In 2015, the Japanese government (Ministry of Economy, Trade and Industry, METI) acknowledged the importance of GIC research in Japan. After reviewing the serious damages caused by the 2011 Tohoku-Oki earthquake, METI recognized the potential risk to the electric power grid posed by extreme space weather. During extreme events, GICs can be concerning even in mid- and low-latitude countries and have become a global issue.

From the scientific and technological aspect, GIC studies are interdisciplinary and include research in Earth's electromagnetism, magnetospheric and ionospheric physics, interplanetary physics, and solar physics. The GIC is determined by the geomagnetically induced electric field (GIE) and the DC characteristics of the electric power grid. GIEs are controlled by magnetic variations in the ground and the Earth's resistivity. Ground magnetic

*Correspondence: sfujita@mc-jma.go.jp

${ }^{1}$ Meteorological College, Kashiwa, Japan

Full list of author information is available at the end of the article variations are composed of magnetic variations caused by magnetospheric and ionospheric disturbances and by currents induced in the ground. The magnetospheric disturbances in turn are driven by coronal mass ejections and other solar disturbances transmitted through interplanetary space. Furthermore, the effective application of a GIC study (e.g., disaster mitigation) requires assessment of how large and how often severe GICs occur in a specific area. Thus, the frequency of severe space weather events also needs to be characterized. At the same time, the heterogeneous distribution of the ground resistivity is important to assess local enhancements of the GIE. Scientists try to understand extreme space weather and predict a realistic GIC, and this special issue of 19 papers publishes recent research achievements about extremely severe space weather and the GIC in the realistic heterogeneous ground resistivity structure.

The influence of the heterogeneous resistivity structure is important for the reproduction of realistic GIEs and GICs from magnetic storm data. Ten papers in this collection address this topic. The influence of the heterogeneous resistivity structure to GIEs is investigated using the geoelectric data obtained continuously at Japanese magnetic observatories (Fujii et al. 2015). Love and Swidinsky (2015) also discuss the geoelectric data from the Kakioka Magnetic Observatory based on a twolayer lithosphere model. Goto (2015) calculates the GIE in the coastal zone with a strong spatial gradient in the resistivity and in the seafloor region with a homogeneous resistivity structure. Alekseev et al. (2015) construct the heterogeneous resistivity structure in the Earth, which is important for the evaluation of the GIEs. Pulkkinen et al. (2015b) demonstrate that the GIEs also can be locally enhanced when the source structure is highly heterogeneous. Next, realistic reproduction of GIEs and 
GICs from the magnetic storm data is reported by several papers. Püthe et al. (2014) calculate the GIE on the ground with heterogeneous resistivity structure driven by a real magnetic storm and accurately predict the GIE using their model. Beggan (2015) performs numerical studies of the GIE driven by the auroral electrojet. Beggan also uses a thin sheet model and estimates the GIC using electric power grid data from the UK. Watari (2015) predicts the GIC by using the transfer function between the observed GICs and the magnetic variations in Hokkaido, Japan. This technique was developed by Pulkkinen et al. (2007). Torta et al. (2014) study the GIC in the electric power grid in Spain by using a plane-wave model with uniform ground resistivity. Last, Xu et al. (2015) evaluate the induction effects driven by the magnetospheric ring current.

In space science and solar physics, detailed dynamics of the severe space weather events are still poorly understood. In addition, because GICs have societal implications, it is important to know the frequency of occurrence of severe space weather events. Therefore, we need to investigate the properties of large solar eruptions that can trigger extreme space weather events and can also transport of high-energy solar particles to the Earth. Nine papers discuss these topics. First, four papers discuss the physical processes associated with extreme magnetospheric disturbances such as the Carrington storm of September 1859 (the largest magnetic storm on record) (Keika et al. 2015), the March 13-14, 1989 magnetic storm (Nagatsuma et al. 2015), and the sudden commencement (SC) in 1940 (the largest SC since 1868) (Araki 2014). Keika et al. (2015) discuss the rapid recovery of the Carrington storm that may have been caused by the flow-out of the ring current associated with fast magnetospheric plasma convection. Nagatsuma et al. (2015) describe magnetospheric processes such as a long duration of the geosynchronous magnetopause crossing during the March 1989 storm, which lacks interplanetary data. They estimate interplanetary magnetic field (IMF) $\mathrm{Bz}$ of about $-50 \mathrm{nT}$ and solar wind speed of about $960 \mathrm{~km} / \mathrm{s}$. Similar to the large SC study by Araki (2014), Kubota et al. (2015) study characteristics of large SCs modeled with a global magnetosphere-ionosphere coupled MHD simulation. Next, three papers deal with statistical studies of the magnetospheric disturbances. Nakamura et al. (2015) study the auroral electrojets, and Minamoto et al. (2015) address the magnetic storms and SCs observed by the Kakioka Magnetic Observatory. The frequencies of occurrence of severe space weather are useful not only to the scientists but also to society. Hayakawa et al. (2015) present the historical records of auroras observed during the Chinese dynasty (Song) in tenth-thirteenth centuries. The last two papers report the characteristics of extreme solar flares and associated interplanetary transport of the energetic solar particles. Maehara et al. $(2012,2015)$ discuss the possibility of a super solar flare (Maehara et al. 2012) based on the solar type of stars observed by the Kepler space telescope. Kubo et al. (2015) present a model reproducing the transport of energetic solar particles that can pose a hazard to satellites.

Between 2011 and 2015, we held annual symposia about extreme space weather and a special symposium celebrating the centennial anniversary of geomagnetic observation at the Kakioka Magnetic Observatory in 2013. The intensive discussions at these symposia between participants from different fields stimulated deep insight into physical processes of these events, and a special issue was planned. In addition, a new Japanese research project about space weather (PSTEP-Project for Solar-Terrestrial Environment Prediction) will be conducted between 2015 and 2019 (http://www.pstep.jp/?lang=en). This project will support research on solar physics, interplanetary physics, magnetospheric physics, and GICs as well as research on the sun-climate relationship. The topics covered in this special issue provided an important springboard for the PSTEP project.

\section{Author details}

${ }^{1}$ Meteorological College, Kashiwa, Japan. ${ }^{2}$ National Institute of Polar Research, Tachikawa, Japan. ${ }^{3}$ NASA Goddard Space Flight Center, Greenbelt, MD, USA.

${ }^{4}$ National Institute of Information and Communications Technology, Koganei, Japan.

Received: 17 March 2016 Accepted: 18 March 2016

Published online: 31 March 2016

\section{References}

Alekseev D, Kuvshinov A, Palshin N (2015) Compilation of 3-D global conductivity model of the Earth for space weather applications. Earth Planets Space 67:108

Araki T (2014) Historically largest geomagnetic sudden commencement (SC) since 1868. Earth Planets Space 66:164

Beggan C (2015) Sensitivity of geomagnetically induced currents to varying auroral electrojet and conductivity models. Earth Planets Space 67:24

Bolduc L (2002) GIC observations and studies in the Hydro-Qùebec power system. J Atmos Sol Terr Phys 64:1793-1802

Fujii I, Ookawa T, Nagamachi S, Owada T (2015) The characteristics of geoelectric fields at Kakioka, Kanoya and Memambetsu inferred from geoelectric potential differences during 2000-2011. Earth Planets Space 67:62

Goto T (2015) Numerical studies of geomagnetically induced current on seafloor and near coastal zones incorporated with heterogeneous conductivity. Earth Planets Space 67:193

Hayakawa H, Tamazawa H, Kawamura AD, Isobe H (2015) Sunspot and aurora records during CE 960-1279 in the Chinese chronicle of the Song dynasty. Earth Planets Space 67:82

Keika K, Ebihara Y, Kataoka R (2015) What caused the rapid recovery of the Carrington storm? Earth Planets Space 67:65

Kubo Y, Kataoka R, Sato T (2015) Interplanetary particle transport simulation for warning system for aviation exposure to solar energetic particles. Earth Planets Space 67:117 
Kubota Y, Kataoka R, Den M, Tanaka T, Nagatsuma T, Fujita S (2015) Global MHD simulation of magnetospheric response of preliminary impulse to large and sudden enhancement of the solar wind dynamic pressure. Earth Planets Space 67:94

Love J, Swidinsky A (2015) Estimation of observatory geoelectric fields induced during intense geomagnetic storms. Earth Planets Space 67:58

Maehara H, Shibayama T, Notsu S, Notsu Y, Nagao T, Kusaba S, Honda S, Nogami D, Shibarta K (2012) Superflares on the solar-type stars. Nature 485:478-481

Maehara H, Shibayama T, Notsu Y, Honda S, Nogami D, Shibarta K (2015) Statistical properties of superflares on solar-type stars based on 1-min cadence. Earth Planets Space 67:59

Minamoto Y, Fujita S, Hara M (2015) Frequency distributions of magnetic storms and SI + SSC-derived records at Kakioka, Memambetsu, and Kanoya. Earth Planets Space 67:191

Nagatsuma T, Kataoka R, Kunitake M (2015) Estimating the solar wind conditions during an extreme geomagnetic storm - a case study of March 13-14 1989 event. Earth Planets Space 67:78

Nakamura M, Yoneda A, Oda M, Tsubouchi K (2015) Statistical analysis of extreme auroral electrojet activities. Earth Planets Space 67:153

Pulkkinen A, Pirjola R, Viljanen A (2007) Determination of ground and system parameters for optimal modeling of geomagnetically induced current flow in technological systems. Earth Planets Space 59:999-1006
Pulkkinen A, Hesse M, Habib S, Van der Zel L, Damsky B, Policelli F, Fugate D, Jacobs W (2009) Solar Shield: forecasting and mitigating space weather effects on high-voltage power transmission systems. Nat Hazards. doi:10.1007/s11069-009-9432-x

Pulkkinen A, Mahmood S, Ngwira C, Balch C, Lordan R, Fugate D, Jacobs W, Honkonen I (2015a) Solar storm GIC forecasting: solar shield extensiondevelopment of the end-user forecasting system requirements. Space Weather. doi:10.1002/2015SW001283

Pulkkinen A, Berabeu E, Eichner J, Viljanen A, Ngwira C (2015b) Regional-scale high-latitude extreme geoelectric fields pertaining to geomagnetically induced currents. Earth Planets Space 67:93

Püthe C, Manoj C, Kuvshinov A (2014) Reproducing electric field observations during magnetic storms by means of rigorous 3-D modelling and distortion matrix co-estimation. Earth Planets Space 66:162

Torta JM, Marsal S, Quintana M (2014) Assessing the hazard from geomagnetically induced currents to the entire high-voltage power network in Spain. Earth Planets Space 66:87

Watari S (2015) Estimation of geomagnetically induced currents based on the measurement data of a Japanese power network. Earth Planets Space 67:77

Xu D, Chen H, Gao M (2015) Observed geomagnetic induction effect on Dst variation under different disturbance intensities of magnetospheric ring current. Earth Planets Space 67:15

\section{Submit your manuscript to a SpringerOpen ${ }^{\odot}$ journal and benefit from:}

- Convenient online submission

- Rigorous peer review

- Immediate publication on acceptance

- Open access: articles freely available online

- High visibility within the field

- Retaining the copyright to your article

Submit your next manuscript at $>$ springeropen.com 